\title{
Direct marketing of cystic fibrosis carrier screening: commercial push or population need?
}

In mid December 1994, the medical genetics community, along with others, was surprised and concerned by a press and television release announcing the direct marketing of cystic fibrosis carrier screening to the public. ${ }^{1}$ The test offered, based on the detection of four common mutations and using DNA from a mouthwash sample sent by mail, also included an information sheet and the possibility of further advice to those concerned at no extra cost. So far, it is too early to know what response and uptake there may have been for the test, but there was certainly considerable coverage of the event in the press and other media.

So why the surprise and why the concern among professionals? The topic of CF carrier screening has, after all, been under intensive study and debate for several years, with a number of pilot studies of different approaches published and in progress. ${ }^{2-8}$ As the commonest recessively inherited disorder in northern Europe, with a carrier frequency of 1 in 20 to 25, it was always likely to attract more commercial interest than rarer conditions and, indeed, industry had already been prominent in developing mutation detection methods appropriate for mass screening. Was not the present development obvious and inevitable?

Why were UK professionals surprised? First, it is probable that this would have been less had the announcement come from the USA, where entrepreneurial involvement in biotechnology and a "direct sell" approach in medicine generally has always been more common than in the UK and most other European countries, and where a systematic provision of primary care for the entire population is lacking. But a further reason lies in the prominence of UK genetic centres in evaluating CF carrier screening, with pilot projects having already critically assessed its possible benefits and problems in the context of primary care, ${ }^{23}$ pregnancy, ${ }^{68}$ and extended family or "cascade" screening. ${ }^{9}$ It is probably fair to state that, in the context of such extensive and thorough evaluation, those involved with $C F$ carrier screening did not expect a development that would bypass not just themselves but all clinicians, introduced with no previous consultation. The final reason for surprise was that four months previously, another press release had indeed announced the development, ${ }^{10}$ but had specifically stated it would be launched "for use at Medical Genetics Centres and in other clinical laboratories". The possibility of direct marketing to the public was at that time firmly denied.

These facts may help to explain why those involved in the field were both surprised and upset at lack of consultation, but does this really matter? If CF carrier screening is really so beneficial and important, why should professionals object to its more general and direct availability, given that in Britain only a minority of regions have implemented it as a service available as part of overall health care? Here the issues become more complex and illustrate the possible dangers of genetic screening programmes that are driven by commercial considerations rather than grounds of "health benefit" in the broadest sense.
First, the pilot programmes, especially those based outside pregnancy, have been far from unanimous in their conclusions about the benefit of CF population carrier screening. All agree that it can be done without causing major stress or other harm, provided that the personnel concerned are trained and skilled in giving information about the test and about results, but that this is very different from the situation where the test is delivered in the context of inexpert or no face to face information. The Nuffield Foundation report on "Ethics of Genetic Screening" 11 used CF screening extensively as the basis for its more general conclusion that such screening should only be introduced along with a comprehensive framework of information that allowed fully informed consent and decision making. It seems unlikely that the ancillary information and counselling service to be provided by the commercial development will in any way fulfil this role, apart from providing help for those concerned by receiving an abnormal result.

Secondly, most pilot studies have shown a marked difference between uptake when testing is offered personally or by mail, raising the question as to whether most of the "demand" is spontaneous or induced. Since commercial success will equate with numbers of people tested, will there be pressure for testing to be maximised, in terms of the way information is written? Will professionals be induced to promote screening, regardless of individual benefits? This is a further reason for concern in a commercially driven situation.

Thirdly, what is the potential for harm in such direct marketing? The laboratory quality is, it should be said, not in doubt here (though only four mutations are tested for) but how many people will misinterpret a normal result as total reassurance or an abnormal result as likely to affect their own health? Perhaps the most worrying aspect is that we may never know the answer, though referrals to expert centres to "pick up the pieces" could increase and should be carefully monitored. Some specific concerns arise: will children be tested? If the policy is no, how will the interests of minors or other third parties be safeguarded? Will abnormal results prejudice insurance? Misinterpretation of this type cannot be ruled out. How will the testing company know that a sample is inappropriate for the screen because of family history or ethnic origins? Disclaimers in the information sheet may avoid legal redress, but will not necessarily help the person involved. All these are issues that can at least be addressed and monitored in a systematic screening service that involves information and counselling as an integral part of the test, but not in a test that is based on direct marketing.

Finally, the main reason why professionals involved in genetics are concerned is the precedent that this development sets for the more general future of genetic testing. This is an area where the dangers, as well as the benefits, have been and are being well researched, especially for such late onset disorders as Huntington's disease, but 
also for broader groups such as familial cancers. All this work has emphasised the need for information and counselling to be regarded as an integral part of the test and for it to be resourced as such, if harm is not to outweigh benefit. Will these conclusions be discarded in the face of commercial pressures and the attraction of possible economies from a purely laboratory approach to testing? Will genetic testing be offered directly to the public for such disorders as breast cancer or Alzheimer's disease, where public concern and possible demand is likely to be as high or higher than for cystic fibrosis? As screening becomes increasingly feasible for common genetic or partly genetic conditions, those working in genetics on both sides of the Atlantic see these threats as real and have repeatedly pointed them out. Will governments need to legislate to control the use and abuse of genetic screening? A year after the issue of the Nuffield report in Britain ${ }^{11}$ and its counterpart in the USA, "Assessing Genetic Risks", ${ }^{12}$ the UK government has made no meaningful response, though an increasing number of other countries have enacted measures of varying strictness. Those who have launched commercial CF carrier screening to the public may have done us all an unwitting service if this development provides the focus for effective regulation, so that genetic testing can be harnessed and used responsibly for the benefit of us all.

PETER S HARPER

Institute of Medical Genetics, University of Wales College of Medicine,
Heath Park,

Cardiff CF4 $4 X N$, UK

1 University Diagnostics. Press release, 12 December 1994.

2 Watson EK, Mayall E, Chaple J, et al Screening for carriers of cystic fibrosis through primary health care services. BMY 1991;303:504-7.
fing

3 Bekker H, Modell M, Denniss G, et al. Uptake of cystic fibrosis testing in primary care: supply push or demand pull? $B M \mathcal{F}$ 1993;306:1584-6.

4 Harris $\mathrm{H}$, Scotcher $\mathrm{D}$, Hartley $\mathbf{N}$, et al. Cystic fibrosis carrier testing in early pregnancy by general practitioners. $B M \mathcal{F}^{1993 ; 306: 1580-3}$.

5 Tamber ES, Bernhardt BA, Chase GA, et al. Offering cystic fibrosis carrier screening to an HMA population: factors associated with utilization. $A m$ f Hum Genet 1994;55:626-37.

6 Wald NJ. Couple screening for cystic fibrosis. Lancet 1991;338:1318-9.

7 Wald NJ, George LM, Wald WW. Couple screening for cystic fibrosis. Lancet 1993;342:1307-8.

8 Livingstone J, Axton RA, Gilfillan A, et al. Antenatal screening for cystic fibrosis: a trial of the couple model. $B M F$ 1994;308:1459-62.

9 Super M, Schwarz MJ, Malone G, Roberts T, Haworth A, Dermody G. Active cascade testing for carriers of cystic fibrosis gene. BMJ 1994;308: 1462-8.

10 Zeneca Group. Press release, 7 August 1994.

11 Nuffield Council on Bioethics. Genetic screening. Ethical issues, 1993.

12 Andrews LB, Fullarton JE, Holtzman NA, Motulsky AG. Assessing genetic risks. Implications for health and social policy. Washington DC: National Academy Press, 1994. 